\title{
Evidence for a trophic cascade on rocky reefs following sea star mass mortality in British Columbia
}

Jessica A Schultz, Ryan N Cloutier, Isabelle M Côté

Echinoderm population collapses, driven by disease outbreaks and climatic events, may be important drivers of population dynamics, ecological shifts and biodiversity. The northeast Pacific recently experienced a mass mortality of sea stars. In Howe Sound, British Columbia, the sunflower star Pycnopodia helianthoides - a previously abundant predator of bottom-dwelling invertebrates - began to show signs of a wasting syndrome in early September 2013, and dense aggregations disappeared from many sites in a matter of weeks. Here, we assess changes in subtidal community composition by comparing the abundance of fish, invertebrates and macroalgae at 20 sites in Howe Sound before and after the 2013 sea star mortality to evaluate evidence for a trophic cascade. We observed changes in the abundance of several species after the sea star mortality, most notably a four-fold increase in the number of green sea urchins, Strongylocentrotus droebachiensis, and a significant decline in kelp cover, which are together consistent with a trophic cascade. Qualitative data on the abundance of sunflower stars and green urchins from a citizen science database show that the patterns of echinoderm abundance detected at our study sites reflected wider local trends. The trophic cascade evident at the scale of Howe Sound was observed at half of the study sites. It remains unclear whether the urchin response was triggered directly, via a reduction in urchin mortality, or indirectly, via a shift in urchin distribution into areas previously occupied by the predatory sea stars.

Understanding the ecological implications of sudden and extreme population declines may further elucidate the role of echinoderms in temperate seas, and provide insight into the resilience of marine ecosystems to biological disturbances. 


\section{Evidence for a trophic cascade on rocky reefs following sea star mass} 2 mortality in British Columbia

3

4 5

$6{ }^{1}$ Earth to Ocean Group, Department of Biological Sciences, Simon Fraser University, Burnaby

7 BC, Canada

$8{ }^{2}$ Coastal Ocean Research Institute, Vancouver Aquarium Marine Science Centre, Vancouver, 9 BC, Canada

$10 *$ Present address: Environmental Services, Stantec, Burnaby, BC, Canada

11

12 Corresponding author:

13 Jessica A. Schultz, ${ }^{1,2}$

141403 Pendrell St., Vancouver, BC, V6G 1S3

15 Email address: Jessica.Schultz@vanaqua.org 


\section{ABSTRACT}

17

18 Echinoderm population collapses, driven by disease outbreaks and climatic events, may be important drivers of population dynamics, ecological shifts and biodiversity. The northeast Pacific recently experienced a mass mortality of sea stars. In Howe Sound, British Columbia, the sunflower star Pycnopodia helianthoides - a previously abundant predator of bottom-dwelling invertebrates — began to show signs of a wasting syndrome in early September 2013, and dense aggregations disappeared from many sites in a matter of weeks. Here, we assess changes in subtidal community composition by comparing the abundance of fish, invertebrates and macroalgae at 20 sites in Howe Sound before and after the 2013 sea star mortality to evaluate evidence for trophic cascade. We observed changes in the abundance of several species after the sea star mortality, most notably a four-fold increase in the number of green sea urchins, Strongylocentrotus droebachiensis, and a significant decline in kelp cover, which are together consistent with a trophic cascade. Qualitative data on the abundance of sunflower stars and green urchins from a citizen science database show that the patterns of echinoderm abundance detected at our study sites reflected wider local trends. The trophic cascade evident at the scale of Howe Sound was observed at half of the study sites. It remains unclear whether the urchin response was triggered directly, via a reduction in urchin mortality, or indirectly, via a shift in urchin distribution into areas previously occupied by the predatory sea stars. Understanding the ecological implications of sudden and extreme population declines may further elucidate the role of echinoderms in temperate seas, and provide insight into the resilience of marine ecosystems to biological disturbances. 
40

41

42

\section{INTRODUCTION}

Echinoderms can be subject to dramatic population fluctuations (Uthicke et al., 2009). Rapid declines are often driven by disease or extreme climatic events. For example, the spread of mass mortality of the black sea urchin, Diadema antillarum, in the 1980s suggests that it was most likely caused by a pathogen (Lessios et al., 1984). The event impacted an estimated 3.5 million $\mathrm{km}^{2}$ of the Caribbean region, causing up to $99 \%$ urchin mortality at some sites (Lessios, 1988). While the precipitous decline of Diadema was a unique occurrence, other echinoderm mass mortality events occur repeatedly. On the Atlantic coast of North America, an amoeboid parasite causes episodic mortality events in green sea urchins, Strongylocentrotus droebachiensis (Jones \& Scheibling, 1985), which are linked to hurricanes and are predicted to increase in frequency with climate change (Scheibling \& Lauzon-Guay, 2010). Similarly, recurring events of wasting disease involving asteroids (sea stars), echinoids (sea urchins) and holothurians (sea cucumbers) in the Channel Islands, California, are associated with climate regime shifts and extreme weather events (Engle, 1994; Eckert et al., 2000).

Because sea stars and sea urchins play key ecological roles in many marine ecosystems, echinoderm population collapses can be important drivers of biodiversity, population dynamics and ecological shifts. In fact, the term 'keystone predator' was originally coined for the purple star, Pisaster ochraceus, after experiments showed that its absence led to significant decreases in intertidal biodiversity (Paine, 1966). Many other echinoderm species have since been shown to influence community composition through predation or herbivory. These effects are apparent on coral reefs following echinoderm population booms (e.g., coral cover declines owing to eruptive crown-of-thorns star, Acanthaster planci (Sano et al., 1984)), or busts (e.g., the transition from 
62 coral- to algae-dominated reefs following the D. antillarum mortality event (Carpenter, 1990)).

63 On temperate rocky reefs, fluctuations in the abundance of herbivorous urchins can also result in 64 major community shifts, from kelp forests to urchin barrens and back again (Estes \& Duggins, 65 1995; Steneck et al., 2003). The northeast Pacific region has recently experienced a protracted mass mortality of sea stars that might rival the magnitude of the Diadema die-off of the 1980s (Johnson, 2016). The event was first noticed on the Olympic coast of Washington in June 2013 (Hewson et al., 2014). In affected sea stars, the signs progress from a loss of turgor pressure, to lesions and ruptures of the body wall and autotomization of arms, and ultimately, disintegration and death (Fig. 1). The wasting syndrome has continued through 2014 and 2015, and has so far affected some 20 species from Alaska to Southern California (Stockstad, 2014). A virus may be involved (Hewson et al., 2014), but the precise causes and contributing factors remain poorly understood. Moreover, little is known so far of the extent and ecological consequences of this sea star mortality event at any location.

Many of the affected seastars were predatory species, raising the possibility of trophic cascades associated with their disappearance and marked community restructuring. In Howe Sound, southern Strait of Georgia, British Columbia, the sunflower star Pycnopodia helianthoides showed signs of advanced wasting in early September 2013. Dense aggregations disappeared from many sites in a matter of weeks (personal observations). This species is one of the world's largest predatory sea stars and it consumes a variety of prey, including echinoderms, gastropods and crustaceans (Herrlinger, 1983; Shivji et al., 1983). In areas that lack other predators such as sea otters Enhydra lutris, such as in Howe Sound, sunflower stars can become the dominant predator of urchins (Duggins, 1983). By altering the abundance and/or distribution 
85 of sea urchins, which in turn can have a conspicuous impact on the abundance of kelp, sunflower

86 stars can influence the formation and persistence of urchin barrens, i.e. areas devoid of kelp

87 because of the grazing activity of urchins (Duggins, 1981). Indeed, most well-substantiated

88 examples of tri-trophic cascades in rocky subtidal ecosystems involve urchins as prey and major

89 herbivore (Pinnegar et al., 2000). We therefore expected that Pycnopodia prey, in particular

90 urchins, would increase in abundance following the disappearance of their major predator,

91 leading to reductions in kelp cover.

92 Here, we evaluate the extent of mortality of $P$. helianthoides in Howe Sound and test

93 whether changes in the benthic community following the rapid decline of this predatory sea star

94 are consistent with the hypothesis of a trophic cascade. We compare rocky reef community

95 composition before and after the mass mortality using quantitative data derived from subtidal

96 transects and qualitative information gathered by citizen scientists. In doing so, we provide

97 empirical evidence that a trophic cascade quickly followed what might be one of the largest

98 wildlife die-off events ever recorded (Johnson, 2016).

100 MATERIALS AND METHODS

101 Subtidal surveys

102 We compared sunflower star abundance and benthic community composition before (2009/2010)

103 and after (2014) the 2013 wasting event using scuba-based surveys of 20 sites in Howe Sound,

104 British Columbia (BC), Canada (Fig. 2). Surveys before the wasting event were conducted as

105 part of a study of rockfish (Sebastes spp) habitat (Cloutier, 2011). We repeated these surveys

106 after the wasting event using the same method, at the same GPS locations, depths (within $2 \mathrm{~m}$ )

107 and time of year (within 14 days). Ten sites were surveyed in early summer (June - July) and 10 
108 sites in late summer (August - October). In all surveys, we recorded the abundance of 18 taxa

109 (species or species groups) of common benthic fishes and invertebrates (Table 1).

110 At each site we surveyed four transects ( $25 \mathrm{~m}$ long by $4 \mathrm{~m}$ wide) at depths between 8 and

$11115 \mathrm{~m}$ (chart datum). We quantified fish and invertebrate abundance by counting all individuals of

112 the target taxa occurring fully or partly within $0.25 \mathrm{~m}^{2}$ quadrats placed at 15 random positions

113 along each transect. We also estimated visually the percent cover of kelp (mainly the genera

114 Agarum, Costaria, Laminaria and Saccharina) within the same quadrats.

115

116 Citizen-contributed (REEF) surveys

117 To verify that the patterns of echinoderm abundance detected at our 20 study sites reflected local

118 trends accurately, we compiled qualitative data on the abundance of sunflower star and green

119 urchin in Howe Sound and adjacent Indian Arm, east of Vancouver, from the Reef

120 Environmental Education Foundation (REEF) citizen science database. Through REEF, scuba

121 divers are trained in species identification and collect data on abundance of species sighted

122 during recreational dives. Divers assign an abundance score from $1-4$ to each species they can

123 positively identify: score $1=$ a single individual, $2=2-10$ individuals, $3=11-100$ individuals

124 and $4=>100$ individuals. Species with no abundance score were assumed to be absent, which

125 we deemed to be a fair assumption given that our target taxa were easy to identify.

126 We extracted the abundance scores of sunflower stars and green sea urchins for all REEF

127 surveys submitted between January 1, 2010 and November 1, 2014 in Washington and BC. To

128 depict trends in abundance over time, we plotted 60-day running averages of the abundance

129 scores for both species. Missing values were filled in using linear interpolation.

130 


\section{Data analyses}

132 We used linear mixed-effects models in the R statistical platform (nlme package; Pinheiro et al.,

133 2015) to compare sunflower star abundance, green urchin abundance and kelp cover before and

134 after the sea star mortality. We obtained sunflower and green urchin abundance for each transect

135 by summing the number of sunflower stars and, separately, green urchins across all quadrats and

136 log-transforming the values prior to analysis. Kelp cover was averaged across all quadrats

137 within each transect. In all cases, we included 'site' as a random effect, and verified the

138 assumptions of normally distributed residuals, homoscedasticity and the absence of leverage by

139 visually examining quantile, residual vs. fitted and Cook's distance diagnostic plots,

140 respectively.

141 To depict graphically site-level changes in the abundance of sunflower stars, green sea

142 urchins and kelp, we plotted the relative difference in abundance for each group at each site.

143 Relative abundance was calculated as the abundance after the mortality event minus the

144 abundance prior to it divided by the mean abundance for both time periods. Abundance was

145 calculated as the total count of each species at each site for sunflower stars and green urchins,

146 and as the average percent cover at each site for algae.

147 To compare overall benthic community composition before and after the sea star

148 mortality, we ran a permutation-based, non-parametric analysis of similarity (ANOSIM; Clarke,

149 1993) using PRIMER (v. 1.0.3; Clarke \& Gorley, 2006). Abundance matrices (species by site)

150 were compiled for each period (i.e., pre- and post-mortality), in which abundance was estimated

151 as the total count of each taxon across transects and/or quadrats at each site. The raw data were

152 square-root-transformed to reduce the influence of very abundant or very rare species. Bray-

153 Curtis similarity coefficients were computed between pairs of sites (Clarke \& Warwick, 2001). 
154 The ANOSIM procedure was carried out on the similarity matrix. ANOSIM generates an R

155 statistic, which varies between 0 (samples are as similar across groups as they are within group)

156 and 1 (all samples within groups are more similar to each other than to any sample across

157 groups) and is tested for difference from zero with a permutation test (in this study, $\mathrm{N}=999$

158 permutations). The differences in benthic assemblages were visualized in a non-metric,

159 multidimensional scaling (MDS) plot in which samples that are more similar in community

160 composition appear closer together than more dissimilar samples. Stress values of $<0.1$ suggest

161 that distances among samples in an MDS plot accurately reflect the extent of community

162 differences (Clarke \&Warwick, 2001). Finally, we conducted an analysis of similarity

163 percentages (SIMPER) to identify the main taxa responsible for any differences observed

164 between pre- and post-mortality assemblages. We considered a taxon to be important to

165 community differences if their individual contribution was $11 \%$ or more, which is twice the

166 expected value if dissimilarity contributions were evenly distributed among all taxa in the

167 analysis (i.e., 100 percent divided by 18 taxa, multiplied by 2). The SIMPER analysis also

168 includes an indication of evenness, expressed as a consistency ratio (CR). CR is the average

169 dissimilarity contribution of a taxon divided by the standard deviation in dissimilarity values of

170 that taxon, for each time period. CR values greater than one suggest that the taxon contributed to

171 dissimilarity between time periods equally across all sites (Terlizzi et al., 2005).

172

173

174

175

176 


\section{RESULTS}

178

179 Sea star mortality

180 At our monitored sites, the abundance of sunflower stars declined by $89 \% \pm 29 \%$ (mean \pm SD),

181 from an average of $0.42( \pm 0.76)$ sunflower stars per $\mathrm{m}^{2}$ before the mortality event to $0.06( \pm$ 182 0.22) individuals per $\mathrm{m}^{2}$ after it (LME: $\mathrm{t}=4.62$, $\mathrm{df}=139, \mathrm{p}<0.0001$; Fig. 3 ). Three sites had no 183 sunflower stars in 2009/2010, and were not included in the percent decline calculation. All 17 184 sites with sunflower stars in 2009/2010 had fewer sunflower stars in 2014.

185 The REEF data included 1568 surveys carried out at 28 sites broadly distributed across 186 BC and Washington between 2010 and 2014. Although sunflower stars were sighted on 98\% of 187 surveys in the years before the mortality event and on $89 \%$ of surveys in the years afterward, a 188 marked decline was evident in their abundance score trajectory (Fig. 5). At this larger geographic 189 scale, sunflower stars started declining in approximately the third week of September, some 15 190 weeks after the first report of seastar wasting in the region.

191 We were unable to detect a geographic pattern in the spread of the sea stars' mortality in 192 our study area because of the speed at which the seastar wasting progressed. It was first 193 observed in Howe Sound (at Whytecliff Park; 49²2'18.4"N, 123¹7'33.8"W) on 2 September, 1942013 , and we then noted it at all of our study sites the following month.

195

196 Benthic community composition

197 There was a significant shift in overall community composition following sea star mortality in 198 Howe Sound (ANOSIM: $\mathrm{R}=0.326, \mathrm{p}=0.001$; Fig. 6), and many species changed in abundance 199 from one period to the next (Table 1). The community shift was largely driven by an increase in 
200 abundance of green urchins (Table 2). Green urchin abundance quadrupled after the near201 disappearance of sunflower stars (LME: $\mathrm{t}=-3.10, \mathrm{df}=139, \mathrm{p}=0.0023$; Fig. 3). This trend is 202 supported by the REEF surveys, although these qualitative data suggest that green urchin 203 numbers began increasing in the first week of September, two to three weeks before the 204 detectable onset of sea star decline (Fig. 5). There was also an increase in the abundance of cup 205 corals, while the numbers of small shrimps and crabs decreased (Table 2). Cumulatively, these 206 four taxa accounted for nearly two-thirds (62\%) of the dissimilarity in benthic community 207 composition before and after the sea star mortality, and their contributions were consistent across 208 sites (CRs > 1; Table 2). Despite their marked decline, sunflower stars did not contribute 209 disproportionately to the dissimilarity between time periods (SIMPER; individual contribution to 210 dissimilarity $=7.15 \%$ ). Overall, within-year similarity was higher after than before sea stars died 211 (SIMPER; average inter-site similarity before $=46.28 \%$, after $=58.11 \%$; Fig. 6), suggesting that 212 communities became more homogeneous following the seastar mortality.

213 In addition to shifts in benthic animal community composition, there was also a change in 214 the abundance of kelp. Kelp cover decreased from $4 \%( \pm 10 \%)$ in $2009 / 2010$ to $<1 \%( \pm 2 \%)$ in 2152014 (LME: $\mathrm{t}=2.669, \mathrm{df}=139, \mathrm{p}=0.0085$; Fig. 3). In all years, the kelp at our sites was almost 216 exclusively the sea colander kelp, Agarum fimbriatum, but also included Saccharina latissima. At the regional scale, the changes in abundance of sunflower stars (decline), green urchins (increase) and kelp (decline) were consistent with a trophic cascade (Fig. 3). At the site

219 level, the patterns were more variable (Fig. 4). Eleven of the 17 sites that had some $P$.

220 helianthoides before the sea star mortality showed increases in green urchin abundance

221 concomitant with declines in sea star abundance (Fig. 4). Eight of these 17 sites showed declines

222 in kelp cover concomitant with increases in green urchin abundance (Fig. 4). A clear alternation 
223 of population trajectories from predators to herbivores to kelp was clear at eight of the 16 sites 224 (Fig 4).

225

226 DISCUSSION

227

228 The wasting disease that affected echinoderms in the northeast Pacific in 2013/2014 heavily

229 impacted populations of sunflower stars, the sea stars that formerly dominated subtidal

230 communities. We found a noticeable shift in benthic community structure following the sea star

231 decline. Community changes were largely driven by changes in the abundance of green sea

232 urchins, cup corals, shrimps and crabs. The temporal coincidence of the alternating trajectories of

233 abundance of sea stars, urchins and kelp, as well as the overlapping distributions and

234 documented trophic linkages among these three taxa, meet the diagnostic criteria of a tri-trophic

235 cascade (Grubbs et al. 2016), triggered by the mass mortality of predatory sunflower stars.

236 Sunflower star densities declined by almost $90 \%$, on average, at our sites in Howe Sound,

237 BC. Such a decline in sea stars rivals the largest magnitudes reported for disease-induced

238 echinoderm mass mortalities (e.g., 70\% of Strongylocentrotus droebachiensis in Nova Scotia

239 (Scheibling \& Stephenson, 1984); 95\% of S. franciscanus in California (Pearse et al., 1977);

$24097 \%$ of Diadema antillarum across the Caribbean (Lessios, 1988)). The percent change in

241 biomass of $P$. helianthoides must be even greater than the change in relative abundance because

242 the sea stars we observed following the mortality event were almost exclusively juveniles $(<6$

$243 \mathrm{~cm}$ diameter). The very large individuals $(>50 \mathrm{~cm}$ diameter) present before the mortality event

244 likely played a proportionately larger role in structuring benthic communities than the juveniles

245 present after the event. The steep decline in sunflower star numbers, occurring some 15 weeks 
246 after the first official sighting of sea star wasting, was clearly evident in the qualitative density

247 scores generated by citizen science (REEF) surveys, which covered a broader geographic area.

248 The time-series of REEF data suggests that sunflower star population levels were somewhat

249 variable, perhaps reflecting variation in the sites surveyed by divers, but largely stable between

250 the first snapshot in 2009/2010 and the onset of the wasting event in 2013. More generally, the

251 benthic species composition of the Strait of Georgia region has remained remarkably stable in

252 recent decades, even in the face of climate regime shifts (Marliave et al. 2011). It therefore

253 seems unlikely that the sea star population declines, and concomitant changes in benthic

254 community composition, could be ascribed to a different, unreported disturbance occurring prior 255 to 2013.

256 The most striking change we observed in community composition was a marked increase

257 in the abundance of green urchins. Overall, green urchins were nearly four times more numerous

258 following the sea star mortality event than before. However, the mechanism of this population

259 increase remains unclear. One possibility is that a recruitment pulse of green urchins coincided

260 with sea star wasting disease, which would have generated a large urchin cohort even in the

261 presence of sunflower stars. Another possibility is that urchin recruits - whether part of a normal

262 or a large cohort - were able to survive better in the absence of abundant sea star predators

263 (Duggins, 1981). The majority of urchins present a year following the seastar mortality were

264 approximately $3-5 \mathrm{~cm}$ in diameter. Green urchins of this size on the east coast of North

265 America are at least three years of age, and possibly more than a decade old (Russel, Ebert \&

266 Petraitis, 1998; Vadas et al., 2000). If these growth rates are similar on the Pacific coast, then

267 most of the urchins we saw could have settled several years before the sea star mortality event.

268 However, urchin growth rates can be highly variable (Vadas et al., 2000), depending on food 
269 supply and temperature (Thompson, 1983; Meidel \& Scheibling, 1999; Pearce et al., 2005),

270 Urchin growth rates have not yet been estimated in BC. A third possible explanation is that the

271 observed increase in urchin abundance resulted from a shift in urchin behaviour following the

272 sea star mortality event. The impact of 'intimidation' on predator-prey interactions can be as

273 important as direct consumption (Lima \& Dill, 1990; Preisser, Bolnick \& Benard, 2005). Under

274 risk of predation, prey individuals alter a suite of behaviours, including habitat choice, foraging

275 range, and time under cover (Werner et al., 1983; Peacor \& Werner, 2001; Trussell, Ewanchuk

$276 \&$ Bertness, 2003; Schmitz, Krivan \& Ovadia, 2004). The effect of sunflower stars on urchin

277 behaviour is well documented. In field experiments in Alaska, both green and purple $(S$.

278 purpuratus) urchins moved away after $P$. helianthoides arms were placed in the centre of urchin

279 aggregations (Duggins, 1981), and urchin distribution shifted rapidly when sea star abundance

280 was experimentally increased (Duggins, 1983). Fear-released urchins could therefore respond by

281 moving from refuges, perhaps in very shallow or deep habitats or in sheltered crevices

282 inaccessible to sea stars (and divers), to more open substrates, making them easier to see and

283 count.

284 The data from REEF surveys support a behavioural rather than a consumptive mechanism

285 for the increase in urchin numbers. Whereas one would expect a delayed increase in urchin

286 numbers following a release from predation (Wangersky \& Cunningham, 1957), green urchin

287 numbers began to increase at approximately the same time as the decline in sunflower stars was

288 evident (Fig. 5). The observed change in green urchin abundance may therefore be due, at least

289 in part, to green urchins modifying their distribution in response to the decline of sunflower stars.

290 Another conspicuous change we observed was a $\sim 80 \%$ reduction in kelp cover (Fig. 3),

291 pointing to a potential trophic cascade triggered by the sea star mortality event. There are many 
292 documented examples of urchin abundance directly influencing the abundance of algae (e.g.

293 Fletcher 1987; Carpenter, 1990; Estes \& Duggins, 1995; McClanahan et al. 1996; Palacin et al.,

294 1998; Scheibling, Hennigar \& Balch, 1999; Villouta et al. 2001). As urchin numbers rise, either

295 due to a large recruitment event (Hart \& Scheibling, 1988) or the absence of a predator (Watson

296 \& Estes, 2011), kelp is rapidly depleted. The alternating directions of population trends of sea

297 stars, urchins and kelp observed here are consistent with the hypothesis of a trophic cascade

298 triggered by the sea star disease. The tri-trophic cascade was clearly evident at the larger scale of

299 Howe Sound (Fig. 3), but detectable at only half of the sites, with a few additional sites showing

300 only part of the cascade (Fig. 4). It is notable that the sites surveyed earliest (i.e., sites 1-5 on

301 Figs 2 and 4) showed an increase in kelp cover, perhaps because not enough time had passed for

302 changes to take place. At other sites where the trophic cascade was not detectable, it is possible

303 that urchins moved elsewhere in search of better food sources (e.g., at sites 17 and 18 on Fig. 4),

304 or that the presence of juvenile sea stars (i.e., site 20 on Fig. 4) resulted in different trophic 305 interactions.

306 In contrast to green urchins, the abundance of many prey species did not increase in the

307 near-absence of sunflower star predators. For example, there was no change in the abundance of

308 red urchins (S. franciscanus) and white urchins (S. pallidus). Neither species is common in

309 Howe Sound, and little is known about the ecology of S. pallidus. However, S. franciscanus

310 may generally be less susceptible to sea star predation than other urchin species because they

311 grow too large to be consumed (Duggins, 1981). Moreover, although crustaceans constitute a

312 significant portion of the diet of sunflower stars (Shivji et al., 1983; Estes \& Duggins, 1995;

313 Lambert, 2000), shrimps and crabs declined following the sea star mortality. Several of the

314 crustaceans we monitored use kelp for both food and habitat. The spot prawn, Pandalus 
315 platyceros, for instance, specifically uses the sea colander kelp as nursery habitat (Marliave \&

316 Roth, 1995). The decline of some crustacean taxa could result from the reduced kelp cover and

317 therefore be a fourth step in the cascade documented here.

318 Another fourth link in the ecological cascade triggered by sea star mortality might

319 involve cup corals. Their increase in abundance was surprising as cnidarians are not normally

320 consumed by P. helianthoides (Shivji et al., 1983; Herrlinger, 1983). However, cup corals are

321 known to fare poorly in areas dominated by macroalgae (Fadlallah, 1983). Contact with algae

322 causes coral polyp retraction, which in turn allows overgrowth by filamentous and coralline

323 algae (Coyer et al., 1993). Increases in density of cup corals can be swift ( $<1$ year), and of the

324 magnitude observed here (3-4 times), after algae disappear (Coyer et al., 1993). Of course, the

325 reduced abundance of kelp and of sea stars may also have allowed for a less obstructed view of

326 the substrate by the observers. As a number of taxa were not monitored in this study, there were

327 likely other changes following the sea star mortality event that we did not detect.

328 In conclusion, our study contributes to understanding the ecological consequences of the

329 northeast Pacific sea star mass mortality. The most notable change was a marked increase in the

330 number of green sea urchins, which might have already had trickle-down effects on other levels

331 of the ecosystem by the time we detected it. It is unclear whether the changes observed will

332 persist as long-term consequences of the near-disappearance of sea stars. Nonetheless, further

333 monitoring will help elucidate the resilience of this ecosystem in the face of acute biological

334 disturbances. Although such a sudden and drastic decline in sea star populations is alarming, it 335 provides a large-scale natural experiment that may advance our understanding of subtidal trophic 336 cascades and invertebrate population dynamics. 


\section{ACKNOWLEDGEMENTS}

340

341 We thank the Vancouver Aquarium Marine Science Centre for all aspects of this study, and in

342 particular the Howe Sound Research team: Jeff Marliave, Donna Gibbs, Laura Borden, and Boaz

343 Hung for support with all aspects of this study. Thank you to volunteer divers Roya Esragh, Marielle

344 Wilson, Brian Caron, Justin Lisaingo, Crystal Kulstar, and Alex Clegg. Comments by Jeff Marliave,

345 Alejandro Frid, Jane Williamson and one anonymous reviewer greatly improved the manuscript.

346 


\section{REFERENCES}

348 Carpenter RC. 1990. Mass mortality of Diadema antillarum. Marine Biology 104:67-77.

349

350

351

352

353

354

355

356

357

358

359

360

361

362

363

364

365

366

367

368

369

370

371

372

373

374

375

376

377

378

379

380

381

382

383
Cloutier RN. 2011. Direct and indirect effects of marine protection: rockfish conservation areas as a case study. MSc Thesis, Simon Fraser University.

Coyer JA, Ambrose RF, Engle JM, Carroll JC. 1993. Interactions between corals and algae on a temperate zone rocky reef: mediation by sea urchins. Journal of Experimental Marine Biology and Ecology 167(1): 21-37.

Dayton PK. 1975. Experimental evaluation of ecological dominance in a rocky intertidal algal community. Ecological Monographs 45:137-159.

Duggins D0. 1981. Interspecific facilitation in a guild of benthic marine herbivores. Oecologia 48:157-163.

Duggins DO. 1983. Starfish predation and the creation of mosaic patterns in a kelp-dominated community. Ecology 64:1610-1619.

Estes JA, Duggins DO. 1995. Sea Otters and Kelp Forests in Alaska: Generality and Variation in a Community Ecological Paradigm. Ecological Monographs 65(1):75-100.

Fadlallah YH. 1983. Population dynamics and life history of a solitary coral, Balanophyllia elegans, from central California. Oecologia 58(2): 200-207.

Fletcher WJ. 1987. Interactions among subtidal Australian sea urchins, gastropods and algae: effects of experimental removals. Ecological Monographs 57 (1): 89-109.

Grubs RD, Carlson JK, Romine JG, Curtis TH, McElroy WD, McCandless CT, Cotton CF, Musick JA. 2016. Critical assessment and ramifications of a purported marine trophic cascade. Scientific Reports 6, 20970.

Hart MW, Scheibling RE. 1988. Heat waves, baby booms, and the destruction of kelp beds by sea urchins. Marine Biology 99:167-176.

Hewson I, Button JB, Gudenkauf BM, Miner B, Newton AL, Gaydos JK, Wynne J, Groves CL, Hendler G, Murray M, Fradkin S, Breitbart M, Fahsbender E, Lafferty KD, Kilpatrick AM, Miner CM, Raimondi P, Lahner L, Friedman CS, Daniels S, Haulena M, Marliave J, Burge CA, Eisenlord ME, Harvell CD. 2014. Densovirus associated with sea-star wasting disease and mass mortality. Proceedings of the National Academy of Sciences 111:17278-17283.

Herrlinger TJ. 1983. The diet and predator-prey relationships of the sea star Pycnopodia helianthoides (Brandt) from a central California kelp forest. M. A. Thesis, San Jose State University.

Johnson, L. (2016, January 21). Sea star wasting disease among worst wildlife die-offs say scientists. CBC News. Retrieved from http://www.cbc.ca/news/canada/british-columbia/seastar-wasting-die-off-1.3414607.

Lambert P. 2000. Sea Stars of British Columbia, Southeast Alaska, and Puget Sound. Royal British Columbia Museum, UBC Press, Vancouver. 
384

385

386

387

388

389

390

391

392

393

394

395

396

397

398

399

400

401

402

403

404

405

406

407

408

409

410

411

412

413

414

415

416

417

418

419

420

Lessios HA. 1988. Mass mortality of Diadema antillarum in the Caribbean: What have we learned? Annual Review of Ecology and Systematics 19:371-393.

Lima SL, Dill LM. 1990. Behavioral decisions made under the risk of predation: a review and prospectus. Canadian Journal of Zoology 68:619-640.

Marliave JB, Gibbs CJ, Gibbs DM, Lamb AO, Young SJF. 2011. Biodiversity stability of shallow marine benthos in Strait of Georgia, British Columbia, Canada through climate regimes, overfishing and ocean acidification In Grillo $\mathrm{O}$ and Verona G (Ed.), Biodiversity Loss in a Changing Planet, 49-74. Rijeka, Croatia: InTech.

Marliave JB, Roth M. 1995. Agarum kelp beds as nursery habitat of spot prawns, Pandalus platyceros Brandt, 1851 (Decapoda, Caridea). Crustaceana 68:27-37.

McClanahan TR, Kamukuru AT, Muthiga NA, Gilagabher Yebio M, Obura D. 1996. Effect of sea urchin reductions on algae, coral and fish populations. Conservation Biology 10(1): 136-154.

Meidel SK, Scheibling RE. 1999. Effects of food type and ration on reproductive maturation and growth of the sea urchin Strongylocentrotus droebachiensis. Marine Biology 134:155-166.

Paine RT. 1966. Food web complexity and species diversity. The American Naturalist 100(910):65-75.

Palacin C, Giribet G, Carner S, Dantart L, Turon X. 1998. Low densities of sea urchins influence the structure of algal assemblages in the western Mediterranean. Journal of Sea Research 39: 281290.

Peacor SD, Werner EE. 2001. The contribution of trait-mediated indirect effects to the net effects of a predator. PNAS 98:3904-3908.

Pearce CM, Williams SW, Yuan F, Castell JD, Robinson SMC. 2005. Effect of temperature on somatic growth and survivorship of early post-settled green sea urchins, Strongylocentrotus droebachiensis (Müller). Aquaculture Research 36:600-609.

Pearse JS, Costa DP, Yellin MB, Agegian CR. 1977. Localized mass mortality of red sea urchin, Strongylocentrotus franciscanus near Santa Cruz, California. Fishery Bulletin.

Pinheiro J, Bates D, DebRoy S, Sarkar D. R Core Development Team. 2015. nlme: Linear and Nonlinear Mixed Effects Models. ... R-project. org/package= nlme. $R$ package version.

Pinnegar JK, Polunin NVC, Francour P, Badalamenti F, Chemello R, Harmelin-Vivien M-L, Hereu B, Milazzo M, Zabala M, D'Anna G, Piptone C. 2000. Trophic cascades in benthic marine ecosystems: lessons for fisheries and protected-area management. Environmental Conservation 27(2): 179-200.

Preisser E, Bolnick D, Benard M. 2005. The high cost of fear: behavioral effects dominate predatorprey interactions. Ecology 86:501-509.

REEF. 2014. Reef Environmental Education Foundation. World Wide Web electronic publication. www.reef.org, downloaded 19 November 2014. 
421

422

423

424

425

426

427

428

429

430

431

432

433

434

435

436

437

438

439

440

441

442

443

444

445

446

447

448

449

450

451

452

Russel MP, Ebert TA, Petraitis PS. 1998. Field estimates of growth and mortality of the green sea urchin, Strongylocentrotus droebachiensis. Ophelia 48:137-153.

Scheibling RE, Stephenson RL. 1984. Mass mortality of Strongylocentrotus droebachiensis (Echinodermata: Echinoidea) off Nova Scotia, Canada. Marine Biology 78:153-164.

Scheibling RE, Hennigar AW, Balch T. 1999. Destructive grazing, epiphytism, and disease: the dynamics of sea urchin-kelp interactions in Nova Scotia. Canadian Journal of Fisheries and Aquatic Sciences 56:2300-2314.

Schmitz OJ, Krivan V, Ovadia 0. 2004. Trophic cascades: the primacy of trait-mediated indirect interactions. Ecology Letters 7:153-163.

Shivji M, Parker D, Hartwick B, Smith MJ, Sloan NA. 1983. Feeding and distribution study of the sunflower sea star Pycnopodia helianthoides (Brandt, 1835). Pacific Science 37:133-140.

Steneck RS, Graham MH, Bourque BJ, Corbett D, Erlandson JM, Estes JA. 2003. Kelp forest ecosystems: biodiversity, stability, resilience and future. Environmental Conservation 29(4):436-459.

Stockstad E. 2014. Death of the stars. Science (New York, N.Y.) 344:464-467.

Thompson RJ. 1983. The relationship between food ration and reproductive effort in the green sea urchin, Strongylocentrotus droebachiensis. Oecologia 56:50-57.

Trussell GC, Ewanchuk PJ, Bertness MD. 2003. Trait-mediated effects in rocky intertidal food chains: predator risk cues alter prey feeding rates. Ecology 96:2049-2055.

Vadas RL Sr., Beal B, Dowling T, Fegley JC. 2000. Experimental field tests of natural algal diets on gonad index and quality in the green sea urchin, Strongylocentrotus droebachiensis: a case for rapid summer production in post-spawned animals. Aquaculture 182:115-135.

Villouta E, Chadderton WL, Pugsley CW, Hay CH. 2001. Effects of sea urchin (Evechinus chloroticus) grazing in Dusky Sound, Fiordland, New Zealand. New Zealand Journal of Marine and Freshwater Research 35(5): 1007-1024.

Wangersky PJ, Cunningham WJ. 1957. Time lag in prey-predator population models. Ecology 38:136-139.

Watson J, Estes JA. 2011. Stability, resilience, and phase shifts in rocky subtidal communities along the west coast of Vancouver Island, Canada. Ecological Monographs 81:215-239.

Werner EE, Gilliam JF, Hall DJ, Mittelbach GG. 1983. An experimental test of the effects of predation risk on habitat use in fish. Ecology 64:1540-1548. 

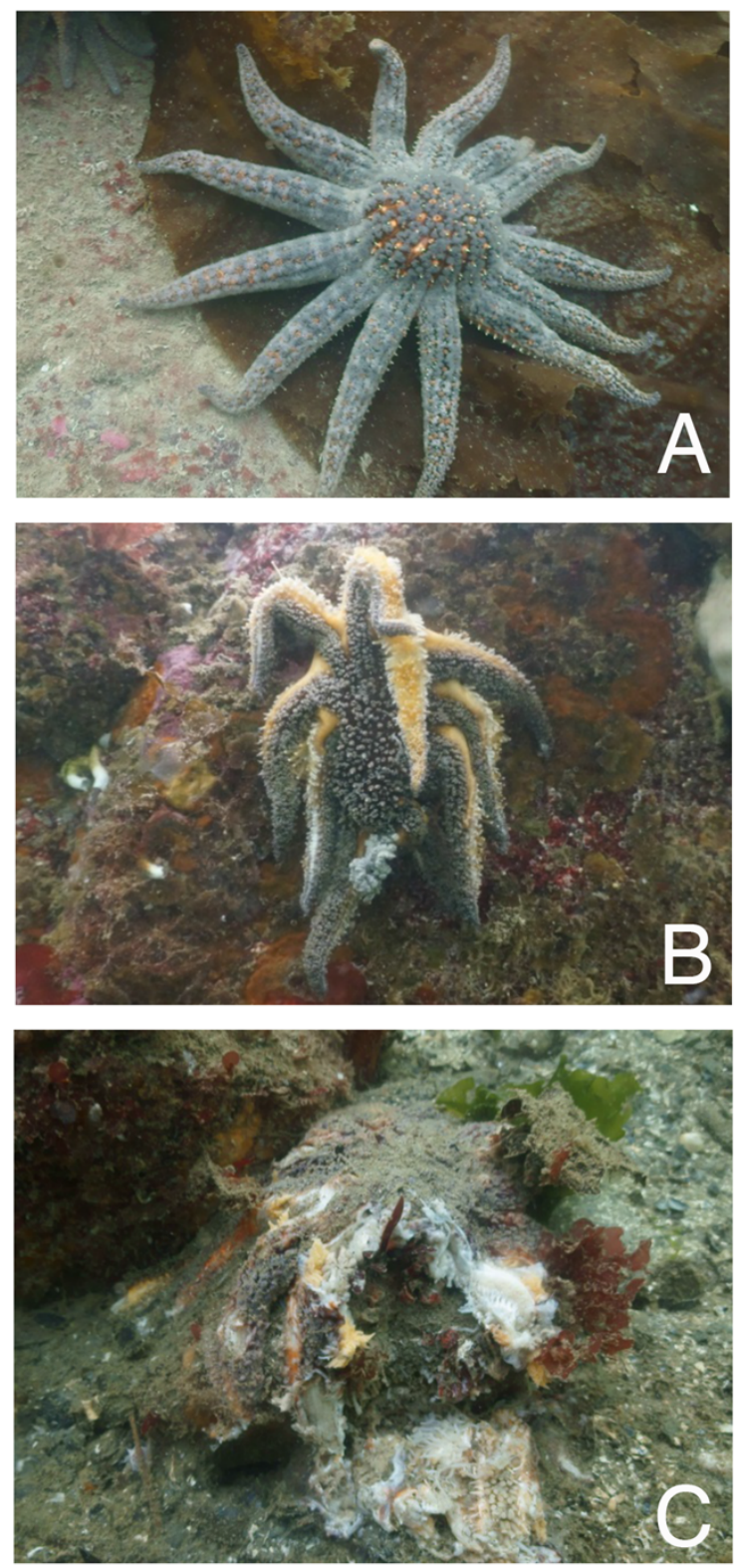

455 Figure 1. Progression of sea star wasting disease. (A) A healthy-looking specimen of $P$. 456 helianthoides moves across the kelp, Agarum fimbiratum. (B) Afflicted sea stars exhibit a loss of 457 turgor pressure and body wall ruptures, followed by (C) limb autotomization, disintegration and 458 death. Photos by Donna Gibbs. 

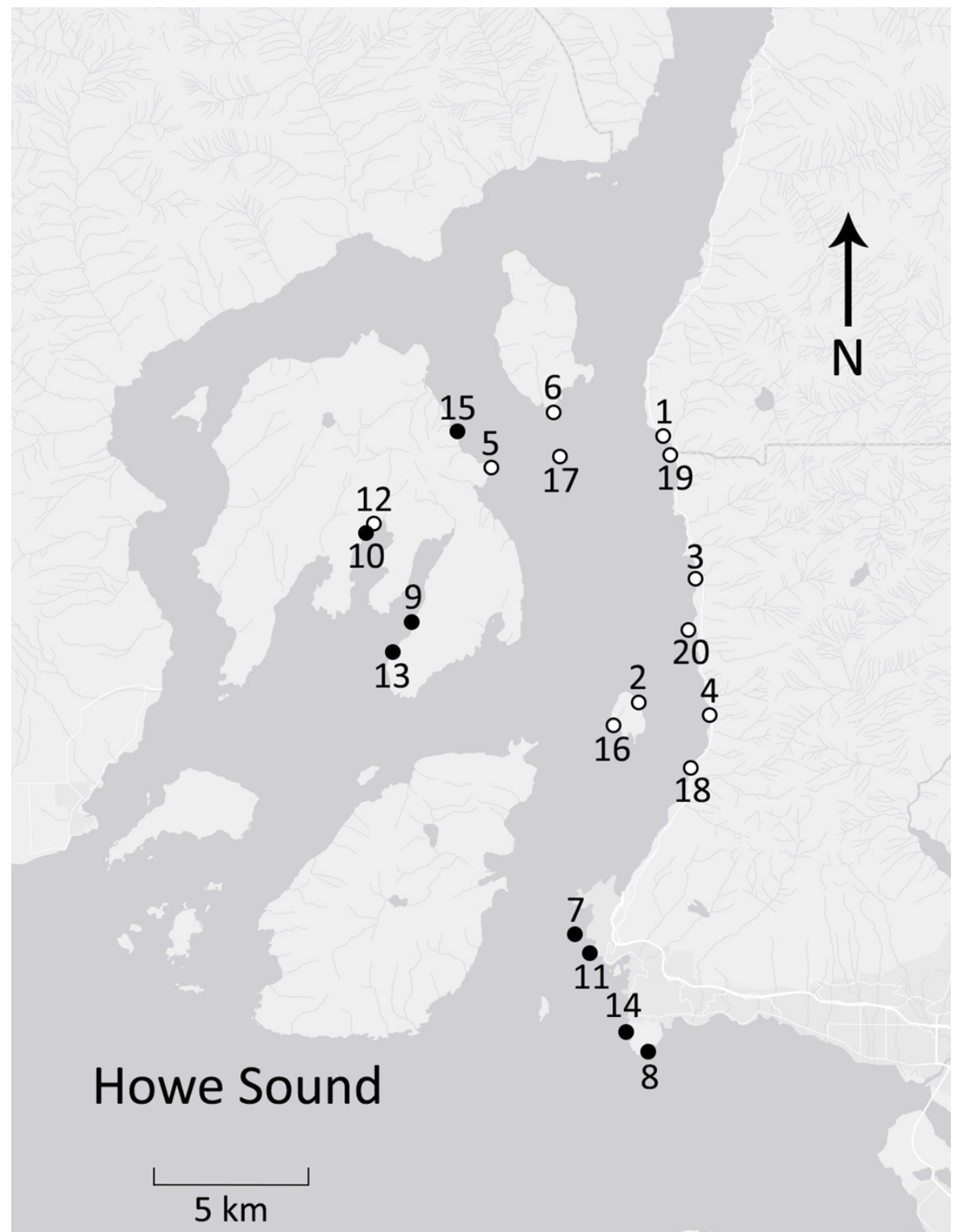

\section{Vancouver}

\section{Map data (C) WorldMap}

Figure 2. Rocky reef survey sites in Howe Sound, British Columbia. Benthic community composition was assessed at each of the 20 sites once in 2009 or 2010 and again in 2014. A mass mortality of sea stars occurred in the summer and fall of 2013 in this area. A site-level trophic cascade following the mortality was detectable at some sites (solid circles) but not others (open circles). (Map data (C) 2015 WorldMap). 
467 Table 1. Taxa recorded during subtidal surveys in Howe Sound, British Columbia. Mean 468 density and standard deviation per $15 \mathrm{~m}^{2}$ are given for each taxon as recorded before and after 469 the sea star mortality event.

Taxon

Species or genera included in taxon

Mean density (SD)

Before

After

Invertebrates

Sunflower star

Green urchin

Red urchin

White urchin

California cucumber

Dungeness crab

Red rock crab

Spot prawn

Squat lobster

Miscellaneous crabs

Miscellaneous

shrimps

Giant Pacific octopus

Cup corals

Benthic fishes

Grunt sculpin

Longfin sculpin

Sailfin sculpin

Scalyhead sculpin

Miscellaneous

sculpins
Pycnopodia helianthoides Brandt, 1835

Strongylocentrotus droebachiensis O. F. Müller, 1776

Strongylocentrotus franciscanus Aggasiz, 1863

Strongylocentrotus pallidus G. O. Sars, 1871

Parastichopus californicus Linnaeus, 1758

Metacarcinus magister Dana, 1852

Cancer productus Randall, 1839

Pandalus platyceros Brandt, 1851

Munida quadrispina Benedict, 1902

Primarily anomurans, including lithode and hermit crabs; several brachyuran genera including Cancer, Pugettia, Scyra, and Oregonia

Primarily Pandalus danae Stimpson, 1857, but also other members of the genus Pandalus, as well as the genera Lebbeus, Eualus, Heptocarpus and possibly others

Enteroctopus dofleini Wülker, 1910

Balanophyllia elegans Verrill, 1864, Caryophyllia alaskensis Vaughan, 1941
$6.4 \quad(11.4) \quad 0.9$

$18.3 \quad(41.0) \quad 77.2 \quad(157.4)$

$\begin{array}{lll}0.4 & (0.9) \quad 0.3\end{array}$

$\begin{array}{llll}1.1 & (2.0) & 0.3 & (0.4)\end{array}$

$6.1 \quad(9.0)$

$0.1 \quad(0.2)$ 0.0

$0.1 \quad(0.3)$

$0.4 \quad(0.7)$

$22.1 \quad(89.1)$

$0.3 \quad(0.8)$

$\begin{array}{ll}4.0 & (9.0)\end{array}$

$0.3 \quad(0.6)$

$21.7 \quad(35.0) \quad 16.3 \quad(23.5)$

$\begin{array}{llll}37.0 & (38.6) & 15.8 \quad(11.2)\end{array}$

$0.1 \quad(0.2)$

0.0

$6.7 \quad(15.8) \quad 22.1$

$\begin{array}{llll}0.1 & (0.2) & 0.1 & (0.2)\end{array}$

$0.2 \quad(0.4)$

$2.7 \quad(4.1)$

$0.1 \quad(0.2)$ 0.0

Nautichthys oculofasciatus Girard, 1858

$0.8 \quad(1.6)$

$1.8 \quad(2.3)$

Cottid genera including Artedius,

Orthanopias, Oligocottus, Radulinus,

Chitonotus and possibly others. 

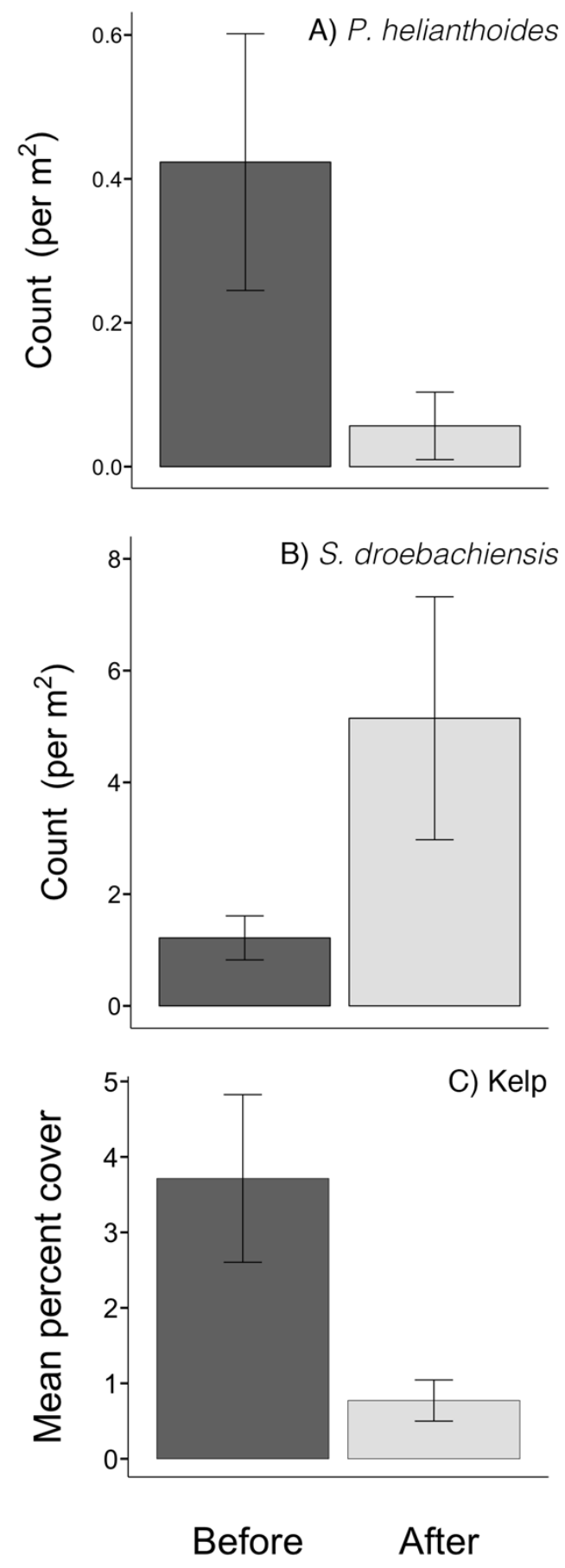

471

472

473

474

475

476

477
Figure 3. Mortality of sea stars, and subsequent change in urchin abundance and kelp cover after sea star mortality. Mean abundance $\left(\right.$ per $\mathrm{m}^{2}$ ) of (A) sunflower stars and (B) green sea urchins, and (C) percent cover of kelp on rocky reefs in Howe Sound, British Columbia, on 80 transects before and after the mass mortality of sea stars in 2013. Error bars represent standard error. The dominant kelp was the sea colander kelp, Agarum fimbriatum. 


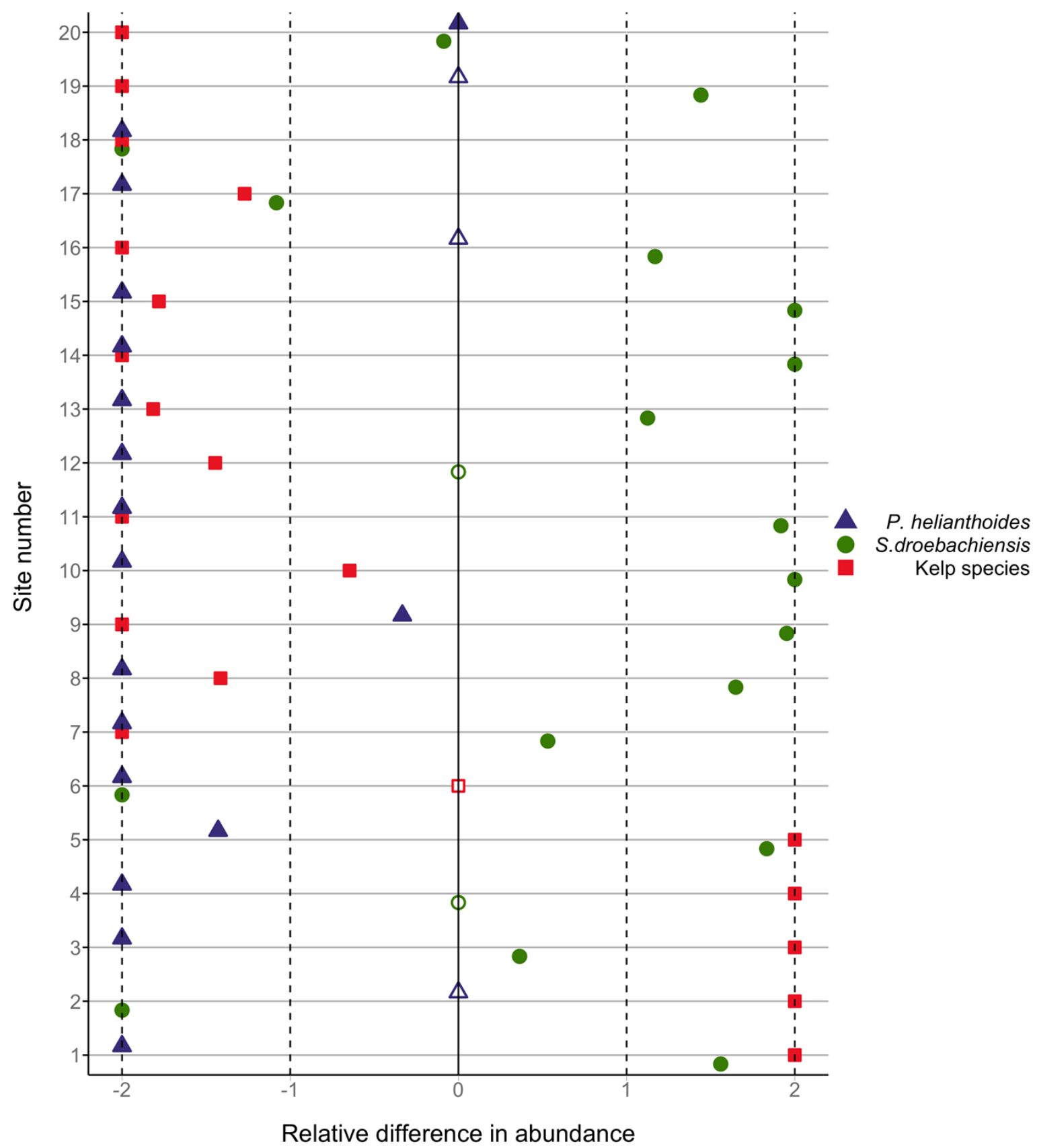

478

479

480

481

482

483

484

485

486

487
Figure 4. Relative difference in abundance of seastars, urchins and kelp by site. The relative difference in total count of sunflower stars (blue triangles) and green urchins (green circles), and the relative difference in the mean percent cover of algae (red squares) before and after the sea star mass mortality. Open symbols indicate sites where population density was zero both before and after the mass mortality. Relative difference was calculated as the change in abundance divided by the mean abundance of both time periods. A relative difference of -2 indicates the population declined to zero. Sites are numbered chronologically according to the order in which they were surveyed, from June to August, 2014. 


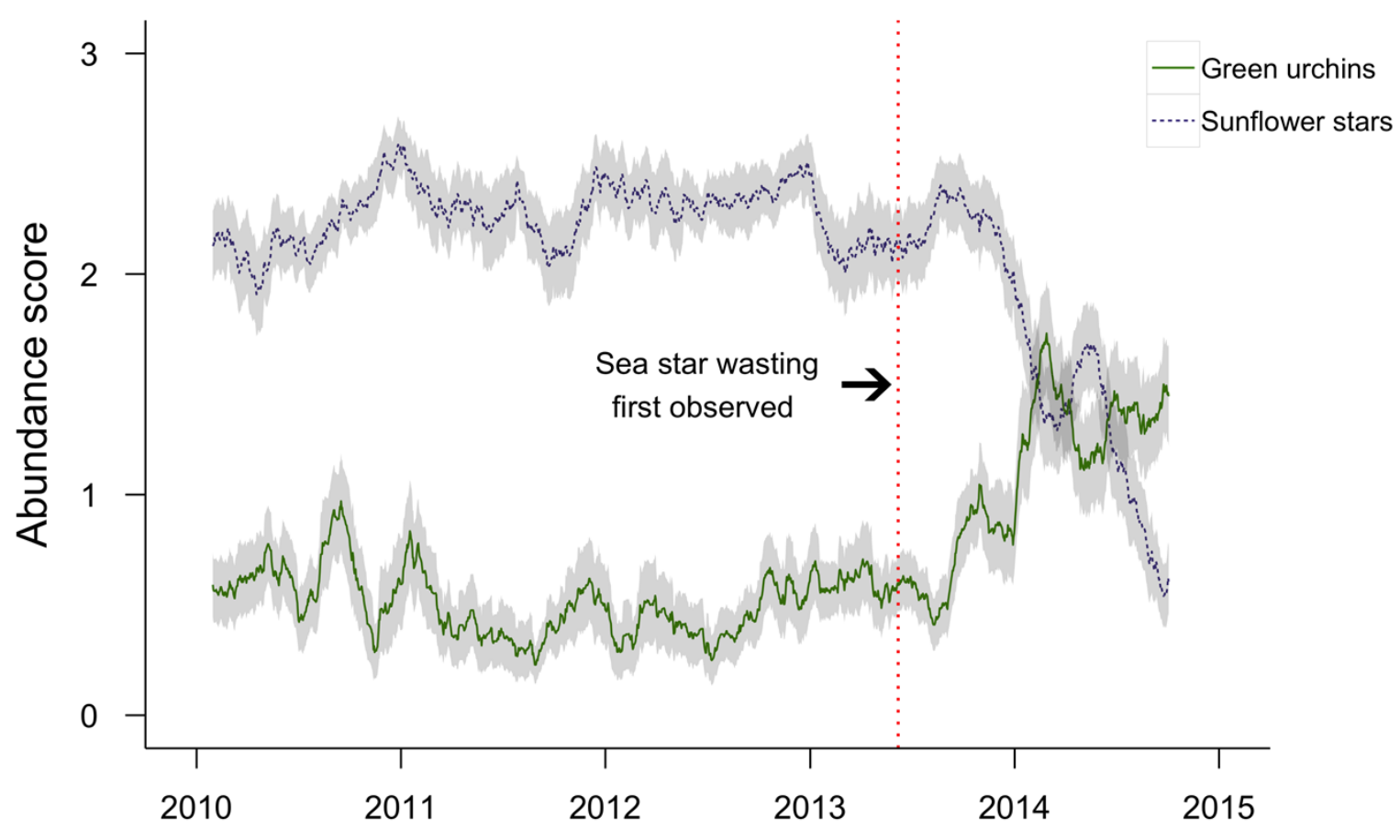

Figure 5. Sunflower star and green sea urchin abundance trajectories. Sixty-day running average abundance scores for green sea urchins (Strongylocentrotus droebachiensis; green solid line) and sunflower stars (Pycnopodia helianthoides; purple dashed line) recorded in REEF surveys from January 2010 to November 2014 in Washington and British Columbia $(\mathrm{n}=1568$ surveys). Grey bands indicate $95 \%$ confidence intervals of the running average. The vertical red dotted line indicates the date of the first recorded observation of sea star wasting syndrome (7 June 2013), which was on the Olympic coast of WA. 


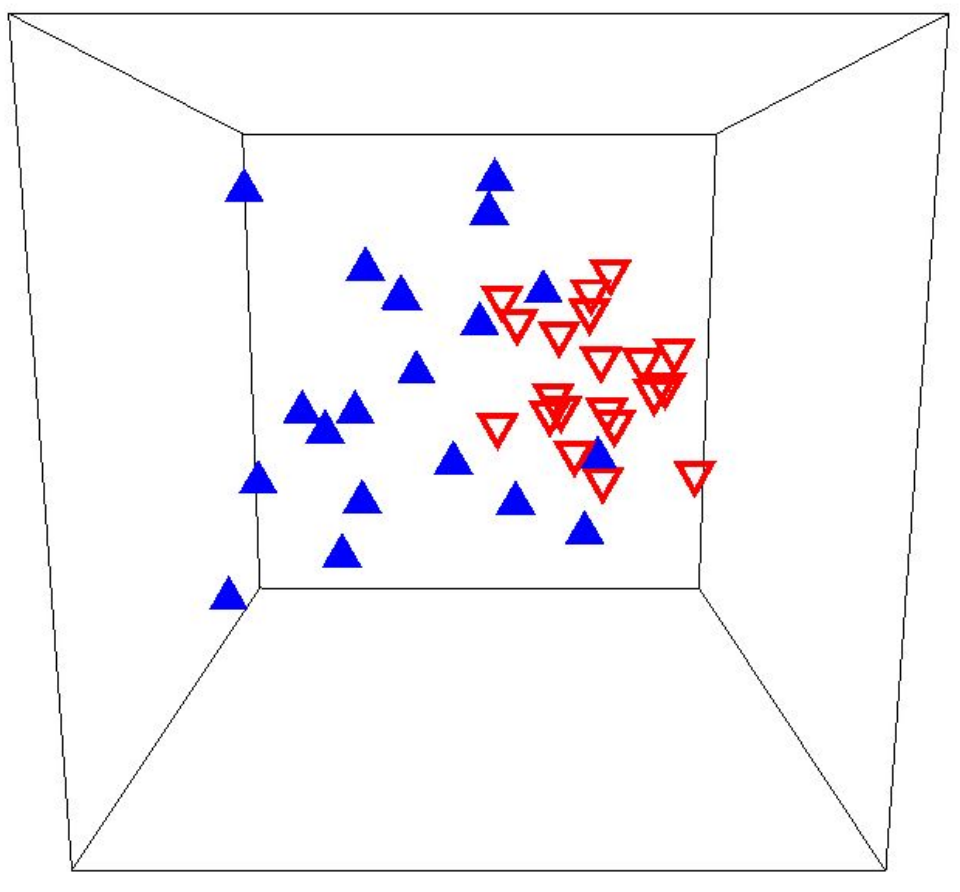

498
Figure 6. Rocky reef species assemblages before and after sea star mortality.

Multidimensional scaling plot of benthic community composition on rocky reefs before (blue triangles) and after (inverted red triangles) the 2013 sea star mass mortality event in Howe Sound, British Columbia. The analysis included 18 fish and invertebrate taxa at 20 sites, surveyed both in 2009/2010 and 2014. The associated stress value (0.13) suggests some distortion in the multivariate representation of the data. 
505 Table 2. Differences in pre- and post-mortality benthic assemblages. The four taxa that 506 contributed disproportionately to dissimilarity in benthic community composition on rocky reefs

507 before and after the 2013sea star mass mortality. Mean densities (\# per $30 \mathrm{~m}^{2} \pm 1 \mathrm{SD}$ ),

508 consistency ratios, and individual and cumulative contributions (in \%) to differences between

509 years are shown. The consistency ratio is calculated as a species' average dissimilarity

510 contribution divided by the standard deviation of dissimilarity values. A consistency ratio $>1$

511 indicates an even contribution to community dissimilarity across sites. The analysis was

512 conducted on square-root-transformed data (see Methods) but untransformed densities are

513 presented here.

\begin{tabular}{|c|c|c|c|c|c|}
\hline \multirow[t]{2}{*}{ Taxon } & \multicolumn{2}{|c|}{$\begin{array}{l}\text { Mean density } \\
\text { (SD) }\end{array}$} & \multirow[t]{2}{*}{$\begin{array}{l}\text { Consistency } \\
\text { ratio }\end{array}$} & \multirow{2}{*}{$\begin{array}{c}\text { Individual } \\
\text { contribution } \\
(\%)\end{array}$} & \multirow{2}{*}{$\begin{array}{c}\text { Cumulative } \\
\text { contribution } \\
(\%)\end{array}$} \\
\hline & Before & After & & & \\
\hline \multirow{2}{*}{$\begin{array}{l}\text { Strongylocentrotus } \\
\text { droebachiensis }\end{array}$} & 18.3 & 77.2 & \multirow[t]{2}{*}{1.09} & \multirow[t]{2}{*}{18.91} & \multirow[t]{2}{*}{18.91} \\
\hline & $(41.0)$ & $(157.5)$ & & & \\
\hline Cup corals & $\begin{array}{c}6.7 \\
(15.8)\end{array}$ & $\begin{array}{c}22.2 \\
(19.1)\end{array}$ & 1.41 & 13.04 & 31.95 \\
\hline Misc. shrimps & $\begin{array}{c}37.0 \\
(38.7)\end{array}$ & $\begin{array}{c}15.9 \\
(11.2)\end{array}$ & 1.3 & 11.29 & 43.23 \\
\hline Misc. crabs & $\begin{array}{c}21.7 \\
(35.0)\end{array}$ & $\begin{array}{c}16.3 \\
(23.5)\end{array}$ & 1.05 & 11.15 & 54.38 \\
\hline Pycnopodia helianthoides & $\begin{array}{c}6.4 \\
(11.4)\end{array}$ & $\begin{array}{c}0.9 \\
(3.3)\end{array}$ & 1.18 & 7.15 & 69.05 \\
\hline
\end{tabular}

514

515 